\title{
É proibido filosofar no ensino médio
}

\section{Se prohíbe filosofar en la enseñanza media}

\author{
Erica Cristina Frau \\ Mestra pela Universidade Estadual de Campinas, Campinas, São Paulo, Brasil. \\ ericafrau@gmail.com
}

Recebido em 28 de novembro de 2017

Aprovado em 28 de maio de 2018

Publicado em 17 de agosto de 2018

RESUMO: O ensino de filosofia no nível médio pode se dar por diferentes caminhos. O presente artigo tem como objetivo fazer inferências sobre a impossibilidade do filosofar na sala de aula, considerando que existe uma filosofia maior que proíbe o seu desenvolvimento. Segundo Deleuze e Guattari, filosofar é a arte de criar conceitos, sendo assim, para que o professor de filosofia consiga promover este devir é necessário resistir às normas e regras estabelecidas pelos fluxos das avaliações finais do ensino médio. Esta resistência se dá por meio de um caminho alternativo, onde o filosofar pode impossibilitar o cumprimento das metas que evidenciam as aprendizagens dos conteúdos que são cobrados nos exames vestibulares e do Exame Nacional do Ensino Médio - ENEM. Essa dicotomia pode evidenciar que é proibido filosofar no ensino médio, pois, mesmo com a permanência da disciplina na grade curricular garantida pela lei, ao fomentar o filosofar, o professor pode ficar sem tempo para contemplar toda lista de conteúdos, competências e habilidades previstas nos documentos oficiais federais e estaduais. Palavras-chave: Devir; Ensino Médio; Filosofar.

RESUMEN: La enseñanza de filosofía en el nivel medio puede darse por diferentes caminos. El presente artículo tiene como objetivo hacer inferencias sobre la imposibilidad del filosofar en el aula, considerando que existe una filosofía mayor que prohíbe su desarrollo. Según Deleuze y Guattari, filosofar es el arte de crear conceptos, siendo así, para que el profesor de filosofía consiga promover este devenir es necesario resistir las normas y reglas establecidas por los flujos de las evaluaciones finales de la enseñanza media. Esta resistencia se da por medio de un camino alternativo, donde el filosofar puede imposibilitar el cumplimiento de las metas que evidencian los aprendizajes de los contenidos que se cobran en los exámenes vestibular y del Examen Nacional de la Enseñanza Media - ENEM. Esta dicotomía puede evidenciar que está prohibido filosofar en la enseñanza media, pues, aun con la permanencia de la disciplina en la red curricular garantizada por la ley, al fomentar el filosofar, el profesor puede quedarse sin tiempo para contemplar toda lista de contenidos, competencias y habilidades previstas en documentos oficiales federales y estatales. Palabras claves: Devenir; Enseñanza Media; Filosofar.

\section{Introdução}

O ensino de filosofia no nível médio pode ser compreendido, hoje, como o cumprimento da lei, mesmo sem termos o conhecimento do seu lugar na grade curricular do novo ensino médio'. Mas, também pode ser compreendido como um acontecimento que possibilita o filosofar. 
Mas, o que é filosofar afinal? Segundo Deleuze e Guattari "a filosofia é a arte de formar, de inventar, de fabricar conceitos" (DELEUZE, 1992, p. 8) é de acordo com esta perspectiva filosófica que desenvolveremos o artigo. Isto porque, buscamos compreender como os docentes têm desenvolvido a atividade de produção conceitual, promovendo a experiência de se pensar filosoficamente no nível médio. O filosofar manifesta-se como exercício de pensar, de pensar por si mesmo, cujo pensamento produzido se dá a partir da contribuição da pedagogia do conceito, onde a atividade do filósofo implica uma dimensão de criação, de criação de conceitos.

O ensino de filosofia encontra-se territorializado no sistema educacional e na sociedade de controle $^{2}$, apresenta-se por meio das leis, dos documentos oficiais federais e dos currículos estaduais que orientam e instituem as normas sobre o ensino de filosofia no nível médio. Cada vez que ocorre uma mudança no sistema educacional como, por exemplo, a Reforma do Ensino Médio aprovada pela lei $13.415 \mathrm{em}$ fevereiro de 2017, o ensino de filosofia se reterritorializa, capturando o novo cenário.

Acontece que o ensino de filosofia, garantido por lei no nível médio, não assegura o que compreendemos por filosofar, pois a sua presença na grade curricular visa atender demandas que têm como objetivo fluxos comerciais voltados para exames vestibulares e o Exame Nacional do Ensino Médio - ENEM, onde a filosofia se transforma em mais uma mercadoria. $O$ fato de a disciplina filosofia estar presente nos currículos oficiais não garantem o seu trato filosófico. Sendo assim, Renata Aspis e Silvio Gallo destacam:

[...] A questão do ensino de filosofia precisa ser tratada filosoficamente; Deleuze e Guattari falaram em uma "pedagogia do conceito": devemos aprender a trabalhar com o conceito, devemos ser aprendizes e artesãos no ofício filosófico. Em O que é a Filosofia? eles afirmaram que apenas uma pedagogia do conceito pode salvá-lo de seus extremos: um enciclopedismo que encerraria a filosofia em si mesma, sem abrir-se ao mundo; e o trato comercial do conceito, sua transformação em mais uma mercadoria que, ao contrário, seria sua perdição por uma mundanização excessiva. (ASPIS e GALLO, 2009, p. 64)

Atualmente, as propostas existentes engessam o ensino de filosofia, mesmo considerando que os documentos oficiais servem para orientar o ensino e não para determinar o que deve ser ensinado. Estes documentos apontam fluxos sobre o desenvolvimento de uma série de conteúdos, competências e habilidades que precisam ser desenvolvidos com os educandos, para, no final do processo, avaliar as aprendizagens. Neste ensino é preciso repetir os moldes, oferecer o mesmo ensino padronizado para atender as demandas do sistema educacional e da sociedade de controle.

\section{É proibido filosofar}

A partir desta construção, é possível formular a hipótese de que é proibido filosofar no ensino médio. Desta construção surgem alguns questionamentos como: Por 
que é proibido? Que filosofar é proibido? O que se proíbe? No entanto, quando afirmamos que é proibido, não estamos dizendo que filosofar é um ato ilegal ou ilícito. A intenção do artigo é apresentar alguns dados concretos sobre a hipótese, investigando as ações que impossibilitam o filosofar e que revelam as inquietações desta proibição.

Estas condições partem dos fluxos canalizados que compõem os currículos oficiais que parametrizam o que minimamente deve ser ensinado-aprendido, engessando e regrando o que deve e pode ser ensinado dentro de cada bimestre ou trimestre do ano letivo. A partir destes fluxos surgem os materiais didáticos que precisam estar em consonância com os currículos para serem aprovados no Programa Nacional do Livro Didático - PNLD, pois somente aqueles que se encontram dentro dos "moldes" serão distribuídos gratuitamente na rede pública e comercializados na rede privada.

Outro fluxo resultante deste processo se faz presente nos conteúdos exigidos nas avaliações, tanto as internas que são aplicadas pelos docentes, no decorrer do processo, para verificar a aprendizagem dos discentes, quanto as que fecham o ciclo do ensino médio, como por exemplo o Exame Nacional do Ensino Médio - ENEM e os vestibulares.

Para que o ensino de filosofia no nível médio contemple a demanda destes fluxos é preciso priorizar alguns procedimentos, trabalhar com conteúdo, competências e habilidades padronizados, ao invés de fomentar o acontecimento do filosofar na sala de aula. Todo esse processo de repetição, passando pela linha do tempo da história da filosofia, abordando correntes filosóficas e os temas mais recorrentes nos últimos exames, parece proibir o filosofar.

\section{Oo parâmetros e as orientações}

O primeiro documento oficial federal, desde a publicação da LDB 9394/1996, que parametriza o ensino de filosofia no nível médio é o PCN - Parâmetros Curriculares Nacionais para o Ensino Médio de 1998, neste encontramos a informação que "do ponto de vista das diretrizes curriculares para o Ensino Médio, definidas pela LDB, em seu Artigo 36, $\S 1^{\circ}$ destaca-se: o domínio dos conhecimentos de Filosofia e de Sociologia necessários ao exercício da cidadania (inciso III)." (BRASIL, 1996, p.45). Neste, podemos perceber que tanto a Filosofia, quanto a Sociologia encontram-se a serviço do desenvolvimento da cidadania, sendo que não fica claro quais os conhecimentos da Filosofia são necessários para atingir a finalidade proposta. O que fica evidenciado no texto é o fato do docente ter que "fazer um esforço para recortar, do vasto universo dos conhecimentos filosóficos, aqueles que imediatamente precisam e podem ser trabalhados no Ensino Médio" (BRASIL, 1996, p.45), e esta informação não aponta para direção alguma.

O documento apresenta também algumas indagações sobre "que Filosofia ensinar? que conhecimentos são necessários? e de que concepção de cidadania estamos falando?" (BRASIL, 1996, p.48), revelando-se por meio de muitas indagações e indicando questionamentos que fomentam o pensamento sobre que competências e habilidades devem ser desenvolvidas nas aulas de Filosofia. Com a intenção de auxiliar os docentes na 
atuação filosófica neste nível de ensino os PCN - Parâmetros Curriculares Nacionais para o Ensino Médio apontam as competências e habilidades a serem desenvolvidas:

Ler textos filosóficos de modo significativo; Ler, de modo filosófico, textos de diferentes estruturas e registros; Elaborar por escrito o que foi apropriado de modo reflexivo; Debater, tomando uma posição, defendendo-a argumentativamente e mudando de posição face a argumentos mais consistentes; Articular conhecimentos filosóficos e diferentes conteúdos e modos discursivos nas Ciências Naturais e Humanas, nas Artes e em outras produções culturais; Contextualizar conhecimentos filosóficos, tanto no plano de sua origem específica, quanto em outros planos: o pessoalbiográfico; o entorno sócio-político, histórico e cultural; o horizonte da sociedade científico-tecnológica. (BRASIL, 1996, p.64)

Estas competências e habilidades revelam-se interessantes e deixam a escolha docente livre para o desenvolvimento de diferentes conteúdos e temas que podem proporcionar o desenvolvimento da cidadania, no entanto, seis anos depois, o MEC - Ministério da Educação publicou o PCN+ Orientações Educacionais Complementares aos Parâmetros Curriculares Nacionais - Ciências Humanas e suas Tecnologias. Neste segundo documento aparecem discussões sobre o trabalho do filósofo-educador para o desenvolvimento de determinadas competências e habilidades.

Este também apresenta eixos temáticos para a elaboração programática das aulas de Filosofia, e destaca que estas “... não devem ser entendidas como listas de tópicos que possam ser tomadas por um currículo mínimo, porque é simplesmente uma proposta, nem obrigatória nem única, de uma visão ampla do trabalho em cada disciplina." (BRASIL, 2002, p. 52). São três eixos temáticos - Relação de poder e democracia, A construção do sujeito moral e O que é Filosofia - dentro de cada um, são apontados temas e subtemas que perpassam por conteúdos específicos e pela história da filosofia, revelando pontos essenciais, embora sem caráter obrigatório.

O terceiro documento, Orientações Curriculares para o Ensino Médio, foi publicado em 2006, apresentando a identidade da filosofia, seus objetivos no ensino médio, suas competências e habilidades, assim como os conteúdos e a metodologia de trabalho. $O$ documento dialoga com a formação inicial do professor de filosofia e faz conexões com a grade da graduação e a grade do ensino médio pensando na produção filosófica e na transmissão do conhecimento. Apresenta uma lista com trinta conteúdos, sendo estes:

1)Filosofia e conhecimento; Filosofia e ciência; definição de Filosofia; 2) validade e verdade; proposição e argumento; 3) falácias não formais; reconhecimento de argumentos; conteúdo e forma; 4) quadro de oposições entre proposições categóricas; inferências imediatas em contexto categórico; conteúdo existencial e proposições categóricas; 5) tabelas de verdade; cálculo proposicional; 6) filosofia pré-socrática; uno e múltiplo; movimento e realidade; 7) teoria das ideias em Platão; conhecimento e opinião; aparência e realidade; 8) a política antiga; a República de Platão; a Política de Aristóteles; 9) 
a ética antiga; Platão, Aristóteles e filósofos helenistas; 10) conceitos centrais da metafísica aristotélica; a teoria da ciência aristotélica; 11) verdade, justificação e ceticismo; 12) o problema dos universais; os transcendentais; 13) tempo e eternidade; conhecimento humano e conhecimento divino; 14) teoria do conhecimento e do juízo em Tomás de Aquino; 15) a teoria das virtudes no período medieval; 16) provas da existência de Deus; argumentos ontológico, cosmológico, teleológico; 17) teoria do conhecimento nos modernos; verdade e evidência; ideias; causalidade; indução; método; 18) vontade divina e liberdade humana; 19) teorias do sujeito na filosofia moderna; 20) o contratualismo; 21) razão e entendimento; razão e sensibilidade; intuição e conceito; 22) éticas do dever; fundamentações da moral; autonomia do sujeito; 23) idealismo alemão; filosofias da história; 24) razão e vontade; o belo e o sublime na Filosofia alemã; 25) crítica à metafísica na contemporaneidade; Nietzsche; Wittgenstein; Heidegger; 26) fenomenologia; existencialismo; 27) Filosofia analítica; Frege, Russell e Wittgenstein; o Círculo de Viena; 28) marxismo e Escola de Frankfurt; 29) epistemologias contemporâneas; Filosofia da ciência; o problema da demarcação entre ciência e metafísica; 30) Filosofia francesa contemporânea; Foucault; Deleuze. (BRASIL, 2006, p.34 e 35)

Esta vasta e desafiadora lista de conteúdos filosóficos é com frequência contemplada pelos exames vestibulares e pelo exame Nacional do Ensino Médio - ENEM. Embora as orientações presentes nos documentos fortaleçam a ideia de que não se trata de um currículo mínimo, a construção dos currículos estaduais e dos materiais didáticos parecem ignorar tal fato. Sendo assim, temos uma disciplina que se encontra presente na grade com uma ou no máximo duas aulas semanais, que acaba tendo que dar conta de mais de 2500 anos de história. Então, o mesmo documento que orienta para o filosofar, acaba "proibindo-o" a partir da indicação de conteúdos que se configuram numa lista de itens cobrados em exames. Não necessariamente

A Filosofia é teoria, visão crítica, trabalho do conceito, devendo ser preservada como tal e não como um somatório de ideias que o estudante deva decorar. Um tal somatório manualesco e sem vida seria dogmático e antifilosófico, seria doutrinação e nunca diálogo. Isto é, tornar-se-ia uma soma de preconceitos, recusando à Filosofia esse traço que julgamos característico e essencial. Desse modo, cabe ensinar Filosofia acompanhando ou, pelo menos, respeitando o movimento do pensar à luz de grandes obras, independentemente do autor ou da teoria escolhida. (BRASIL, 2006, p.35)

Mas, como é possível ensinar filosofia e garantir justiça nos processos de seleção diante desta dicotomia? Os três documentos oficiais citados e a cobrança dos conteúdos filosóficos explorados nos vestibulares e no Exame Nacional do Ensino Médio - ENEM são exemplos do que podemos compreender como o ensino de uma filosofia maior, onde o acontecimento do filosofar fica muito vulnerável e por que não dizer, proibido. 


\section{Da filosofia maior para a filosofia menor}

Enquanto algumas práticas docentes podem ser mera reprodução das regras estabelecidas pelo ensino de uma filosofia maior com o intuito de atingir as metas estabelecidas pelo sistema, levando os estudantes a terem maior êxito no desempenho dos conteúdos de filosofia nesses exames, podemos considerar que é proibido filosofar no ensino médio de acordo com o que foi estabelecido como filosofar neste artigo.

Para exemplificar melhor $\circ$ que se pretende com a utilização do conceito de uma filosofia maior, podemos observar o apontamento presente no livro $O$ ensino da filosofia no limiar da contemporaneidade: o que faz o filósofo quando seu ofício é ser professor de filosofia? de Rodrigo Gelamo, onde apresenta:

A crítica ao fazer maior da filosofia pode ser encontrada na obra Diferença e repetição, na qual Deleuze (1968) mapeia os pressupostos do pensamento filosófico. Para ele, existem dois tipos de pressupostos: os objetivos e os subjetivos. Os pressupostos objetivos, utilizados pela ciência e pela filosofia, são supostos em um teorema, em um conceito ou em um problema; sua função é servir de lei, funcionando como aquilo que inquestionavelmente todos deveriam saber. (GELAMO, 2009, p.86)

Gelamo destaca que os pressupostos objetivos da filosofia servem a este fazer maior que conceituamos filosofia maior; em continuidade aponta a necessidade de compreendermos o funcionamento desta, para não nos deixarmos dominar pela dogmatização que a caracteriza, buscando assim o desenvolvimento da filosofia por um modo menor, onde é possível produzir diferenças. Vejamos:

Poderíamos dizer que, para Deleuze, quando a filosofia se esta-
belece nessas imagens dogmáticas do pensamento, ou quando
o filósofo se vincula às linhas majoritárias dos temas e problemas
históricos, ela se enquadra no modo maior de filosofar. Essa vincu-
lação não permite a produção da diferença, seja no pensamento,
nos problemas ou nas soluções. No entanto, a filosofia pode ser
feita de um modo menor quando problematiza linhas de intensidade
que não se vinculam àquilo que uma maioria problematiza, esc
pando das imagens dogmáticas do pensar. (GELAMO, 2009 p. 96)

Um exemplo sobre esse desejo do que pode ser praticado encontra-se no artigo Filosofia da diferença: apontamentos em torno da aprendizagem do pensamento em filosofia, de Américo Grisotto. $O$ trecho citado faz referência sobre as possibilidades, os ensaios, as experimentações filosóficas que podem acontecer na sala de aula quando se pretende desenvolver as diferenças e as criações, saindo do maior, operando no que consideramos o ensino de uma filosofia menor: 
Em consonância com esta perspectiva, o que se deseja é que a aprendizagem do pensamento filosófico se sirva menos do exercício de verdades comuns a todos e passe a investir muito mais na multiplicidade das abordagens e nas criações, de modo que propostas inusitadas insurjam e liberem as forças do pensamento. Justamente a esse propósito é que se defende que o ato de reter um determinado conteúdo deve ser visto com menos importância do que aquele de uma aprendizagem interessada. (GRISOTTO, 2012, p. 183)

Neste trecho podemos encontrar o exemplo do desejo desse acontecimento que libera as forças do pensamento, que descreve a possibilidade do filosofar nas aulas de filosofia no nível médio, que busca conhecer esse devir que se dá no acontecimento da criação do conceito.

Outro exemplo que podemos apresentar aponta sobre a prática docente. No artigo Formação de Professor de Filosofia: entre o saber e o fazer, Elisete Tomazetti e Simone Moraes destacam reflexões sobre as fragilidades da formação inicial e os possíveis desafios que o professor recémformado pode encontrar dentro da sala de aula quando fizer acontecer o saber apreendido.

Ao filósofo, formado numa licenciatura, cabe a tarefa de pensar uma pedagogia filosófica. No entanto, didáticas, metodologias, formas e objetos de avaliação não estão separados de uma noção de Filosofia. Essa, em sua singularidade, requer formas e concepções de ensino também específicas, próprias à possibilidade de se ensinar e se aprender a filosofar. A necessária justificação de um fazer filosófico em sala de aula é, pois, filosófica. Exige o debate e a definição de um dos temas centrais da história da Filosofia: "O que é filosofia?". (TOMAZETTI e MORAES, 2016, p. 748 e 749)

A difícil tarefa para os docentes, sejam recém-formados ou não, encontrase na complexa relação entre o desenvolvimento das metodologias de ensino, dos recursos didáticos, dos tipos de abordagem, da problematização, das avaliações e do fazer acontecer o filosofar, sobre essa singular especificidade de fazer filosofia e não de repetir a história da filosofia, pois segundo Deleuze "[...] o devir não é história; a história designa somente o conjunto das condições, por mais recentes que sejam, das quais se desvia a fim de 'devir', isto é, para criar algo novo." (DELEUZE, 1992, p. 211). Nesse sentido, o desafio da possibilidade do devir-acontecimento vai depender da atuação do docente, vai depender das ações e das escolhas para viabilizar o filosofar.

$\mathrm{Na}$ sala de aula, a aprendizagem escapa da máquina de controle que é a metodologia de ensino, e no caso específico do ensino de filosofia, a relação ensino-aprendizagem torna-se ainda mais complexa, principalmente quando se busca o desenvolvimento da aprendizagem do filosofar. Esse desenvolvimento escapa do molde, ultrapassando as fronteiras que tentam controlar o ensino, que precisam de regras e formas para não perder o domínio. Nessa complexa relação, a avaliação também pode ser considerada máquina de controle, pois compete a ela verificar a aprendizagem, e 
em se tratando de aprender a filosofar, avaliar este acontecimento requer a permissão de singularidades ímpares, o que nem sempre é fácil e simples de se executar.

Pensando ainda na frágil ligação que existe entre o ensino e a aprendizagem, e buscando compreender o que é o filosofar no processo de aprendizagem em filosofia, Américo Grisotto resgata a filosofia da diferença e fomenta a criação de conceitos a partir dos pensamentos filosóficos existentes.

No processo da aprendizagem em filosofia, cujo material de manuseio é o legado do pensamento, o que se espera de todo aprendiz é que intervenha por meio da criação. Os signos a que se submete $e$ as singularidades sob sua escolha the são únicos, o que the permite a inserção de aspectos peculiares em suas construções conceituais. (GRISOTTO, 2012, p. 185)

Segundo Deleuze "[...] a grandeza de uma filosofia avalia-se pela natureza dos acontecimentos aos quais seus conceitos nos convocam, ou que ela nos torna capazes de depurar em conceitos" (DELEUZE, 1992, p. 43), então a partir das construções conceituais que ocorrem por meio da traição da leitura dos clássicos da tradição filosófica "[...] os conceitos vão, pois, ao infinito e, sendo criados, não são jamais criados do nada" (DELEUZE, 1992, p. 27). Todo esse processo criativo depende do trabalho desenvolvido dentro da escola pelo professor de filosofia, compete a ele viabilizar ou não o que chamamos de filosofar.

\section{Considerações finais}

Baseado no pensamento deleuziano buscamos encontrar o desenvolvimento do filosofar como acontecimento no nível médio, revelando-se como experiência de pensamento, escapando da regra estabelecida pelo desenvolvimento do ensino de uma filosofia maior, promovendo o desafio de fazer com que o estudante de filosofia pense por si mesmo de forma autônoma, sem a intenção de decorar conteúdos filosóficos para ter êxito em exames. No entanto, trata-se de uma busca, pois é sabido que "não é qualquer ensino que cumprirá esse tipo de papel" (GALLO, 2017, p.37), a reprodução de conteúdos e a passagem pela história da filosofia como repetição pode-se afirmar que "será um ensino inócuo e mesmo, arrisco-me a dizer, prejudicial” (GALLO, 2017, p.37), afirma Silvio Gallo em seu artigo Experimentar a filosofia no Ensino médio: o desafio de pensar por si mesmo.

Resistir às proibições é encontrar um modo menor de operar dentro do modo maior, é aproveitar o momento da aula para fazer o devir acontecer. No entanto, o docente que escoIher percorrer este caminho, dependendo da forma como atuar, deve saber que ao promover o filosofar pode privar o estudante do ensino médio de tomar contato com os conteúdos que no final do processo serão cobrados nos exames vestibulares e no ENEM, sendo está ação uma difícil escolha, uma vez que o filósofo-professor, muitas vezes fica dividido entre a possibilidade e a impossibilidade do filosofar dentro dos fluxos da nossa sociedade de controle. 


\section{Referências}

ASPIS, R. P. L.; GALLO, S. D. O. Ensinar Filosofia: um livro para professores. São Paulo: Atta Midia e Educação, 2009.

BRASIL. Base Nacional Comum Curricular. Brasília: Ministério da Educação, Disponível em: http://basenacionalcomum.mec.gov.br/ Acesso em 20 jul. 2017.

. Decreto 9.099 de 18 de julho de 2017. Dispõe sobre o Programa Nacional do Livro e do Material Didático.

Filosofia no Enem: um estudo analítico dos conteúdos relativos à Filosofia a longo das edições do ENEM entre 1998 e 2011/Ester Pereira Neves de Macedo. Brasília, DF Instituto Nacional de Estudos e Pesquisas Educacionais Anísio Teixeira, 2015.

. Guia de livros didáticos: PNLD 2018: Filosofia. - Brasília: Ministério da Educação, Secretaria de Educação Básica, 2017.

. Lei 13.415 de 16 de fevereiro de 2017.

. Matriz de Referência para o ENEM. Disponível em: http://download.inep.gov. br/educacao_basica/enem/downloads/2012/matriz_referencia_enem.pdf Brasília, DF Instituto Nacional de Estudos e Pesquisas Educacionais Anísio Teixeira.

. Orientações curriculares para o ensino médio; volume 3. Ciências Humanas e suas tecnologias. Brasília: Ministério da Educação, 2006.

Parâmetros Curriculares Nacionais para o Ensino Médio. Ciências Humanas e suas tecnologias. Brasília: Ministério da Educação/Secretaria da Educação Média e tecnológica. 1998.

PCN+ Orientações Educacionais Complementares aos Parâmetros Curriculares Nacionais - Ciências Humanas e suas tecnologias. Brasília: Ministério da Educação/Secretaria da Educação Média e tecnológica. 2002.

CERLETTI, A. A. Ensinar filosofia: da pergunta filosófica à proposta metodológica. In: KOHAN, Walter Omar. (Org.). Filosofia: caminhos para seu ensino. Trad. Ingrid Muller Xavier. Rio de Janeiro: DP\&A, 2004.

. O ensino da Filosofia como problema filosófico. Belo Horizonte: Autêntica, 2009.

DELEUZE, G. Conversações. Tradução Peter Pál Pelbart. Rio de Janeiro: Editora 34, 1992.

DELEUZE, G.; GUATTARI, F. 0 que é a filosofia? 2. ed. Trad. Bento Prado Jr. Alberto Alonso Munõz. Rio de Janeiro, RJ: 34, 1992.

GELAMO, R. P. O ensino da filosofia no limiar da contemporaneidade: o que faz o filósofo quando seu ofício é ser professor de filosofia? São Paulo: Cultura Acadêmica, 
GRISOTTO, A. Filosofia da diferença: apontamentos em torno da aprendizagem do pensamento em filosofia. In: ETD - Educ. Tem. Dig., Campinas, v.14, n.1, p.179-198, jan./ jun. 2012.

\section{TOMAZETTI, E; MORAES, S. Formação do professor de filosofia: entre o saber e o} fazer. In: Revista Even. Pedagóg. Número Regular: Formação de Professores e Desafios da Escola Sinop, v. 7, n. 2 (19. ed.), p. 744-758, jun./jul. 2016.

\section{Notas}

${ }^{1}$ A lei 13.415/2017 altera a LDB 9.394/1996. "Art. 35-A. A Base Nacional Comum Curricular definirá direitos e objetivos de aprendizagem do ensino médio, conforme diretrizes do Conselho Nacional de Educação, nas seguintes áreas do conhecimento: I - linguagens e suas tecnologias; II - matemática e suas tecnologias; III - ciências da natureza e suas tecnologias; IV - ciências humanas e sociais aplicadas." O ensino de filosofia encontra-se na dependência da publicação da BNCC - Base Nacional Comum Curricular, para saber qual será o seu lugar no ensino médio, pois a única informação concreta sobre sua continuidade encontra-se presente no "§ $2^{\circ} \mathrm{A}$ Base Nacional Comum Curricular referente ao ensino médio incluirá obrigatoriamente estudos e práticas de educação física, arte, sociologia e filosofia."

${ }^{2} \mathrm{O}$ termo sociedade de controle foi utilizado por Deleuze para demonstrar que estamos deixando para trás as sociedades disciplinares de Foucault, no artigo "Post-scriptum sobre as sociedades de controle". (DELEUZE, 1992, p. 219 - 226)

\section{Correspondência}

Erica Cristina Frau - Rua Cândido Mota, 186, Fundação da Casa Popular, Governo do Estado de São Paulo Diretoria de Ensino Região Campinas Oeste, CEP 13.031-385, Campinas, São Paulo, Brasil.

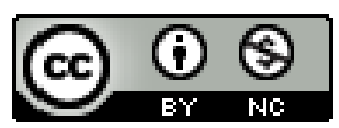

This work is licensed under a Creative Commons Attribution-NonCommercial 4.0 International (CC BY-NC 4.0) 